\title{
Association between temporomandibular disorders and abnormal head postures
}

\section{Evandro Francisco FAULIN(a) Carlos Gramani GUEDES(a) Pedro Paulo FELTRIN ${ }^{(b)}$ Cláudia Maria Mithie Suda Costa JOFFILEY(c)}

\footnotetext{
(a) Universidade de Brasília - UnB, Faculdade de Ciências da Saúde, Departamento de Odontologia, Brasília, DF, Brazil.

(b)São Leopoldo Mandic - SLMANDIC, Dental Research Center, Odontologia, São Paulo, SP, Brazil.

(c) Universidade de Brasília - UnB, Dental Prostheses, Odontology, Brasília, DF, Brazil.
}

Declaration of Interests: The authors certify that they have no commercial or associative interest that represents a conflict of interest in connection with the manuscript.

Corresponding Author:

Evandro Francisco Faulin

E-mail:vanfaulin@gmail.com

DOI: 10.1590/1807-3107BOR-2015.vol29.0064

Submitted: Sep 02, 2014

Accepted for publication: Jan 15, 2015

Last revision: Apr 27, 2015
Abstract: This study examines the possible correlation between the prevalence of temporomandibular disorders (TMD) and different head postures in the frontal and sagittal planes using photographs of undergraduate students in the School of Dentistry at the Universidade de Brasília - UnB, Brazil. In this nonrandomized, cross-sectional study, the diagnoses of TMD were made with the Research Diagnostic Criteria (RDC)/TMD axis I. The craniovertebral angle was used to evaluate forward head posture in the sagittal plane, and the interpupillary line was used to measure head tilt in the frontal plane. The measurements to evaluate head posture were made using the Software for the Assessment of Posture (SAPO). Students were divided into two study groups, based on the presence or absence of TMD. The study group comprised 46 students and the control group comprised 80 students. Data about head posture and TMD were analyzed with the Statistical Package for the Social Sciences, version 13. Most cases of TMD were classified as degenerative processes (group III), followed by disk displacement (group II) and muscle disorders (group I). There was no sex predominance for the type of disorder. No association was found between prevalence rates for head postures in the frontal plane and the occurrence of TMD. The same result was found for the association of TMD diagnosis with craniovertebral angle among men and women, and the group that contained both men and women. Abnormal head postures were common among individuals both with and without TMD. No association was found between head posture evaluated in the frontal and sagittal planes and TMD diagnosis with the use of RDC/TMD.

Keywords: Temporomandibular Joint Disorders; Cervical Vertebrae; Postural Balance.

\section{Introduction}

Anatomic correlations between the craniomandibular complex and the cervical spine have been primarily assessed in clinical studies. Attempts to establish a correlation between variables, particularly the cervical posture and head posture, have yielded contradictory results. Head posture has been studied by several authors, most often in association with craniocervical changes, ${ }^{1}$ temporomandibular disorders (TMD), ${ }^{2}$ mandibular development and function, ${ }^{1,3,4}$ type of occlusion, ${ }^{5}$ changes 
in head posture from ocular reasons, ${ }^{6}$ and changes inherent to the cervical spine. ${ }^{7}$

Experimental trials have demonstrated a clear functional correlation between cervical posture and changes in mandibular and condylar positions. The military head posture, the forward head posture, and head tilts redirect the mandibular position. ${ }^{8}$ The forward head position moves the mandibular condyle from a normal position to a higher and more posterior region in the mandibular fossa than in normal head posture. ${ }^{9}$ Moreover, painful stimuli in the cervical region may lead to pain in the facial region. ${ }^{10,11}$

Some clinical studies have found that the use of diagnostic criteria for TMD associated with photographic and magnetic resonance imaging analyses do not confirm the correlation between TMD and head and cervical postures. ${ }^{12,13}$ However, some other studies, which identified signs and symptoms of TMD and analyzed head posture in the sagittal plane, have found a correlation between these two variables. ${ }^{14,15}$

The definition of a functional association between TMD and head prevalence is still controversial according to clinical studies and due to the method differences. This study evaluated the correlation between TMD prevalence and head posture with the use of RDC/TMD and the evaluation of head posture in frontal and sagittal planes using photographs of a group of undergraduate students of the School of Dentistry, Universidade de Brasília - UnB, Brazil.

\section{Methodology}

\section{Study design and participants}

This cross-sectional study included 126 students (75 women; mean age, 25 years) enrolled in the School of Dentistry, Universidade de Brasília - UnB, Brazil. All students were enrolled in the last two semesters of the undergraduate course "Integrated Clinics 1 or 2 "course. The evaluations were conducted in the University Hospital of Brasília. Data were collected from August 2008 to July 2009. All participants signed an informed consent term before the evaluations were made. The study was approved by the Ethics and Research Committee at the Universidade de Brasília - UnB. Registration Project 124/2008.

\section{Exclusion criteria}

Criteria for exclusion from the study included previous oral or maxillofacial surgery, any type of major head or neck trauma, one or more teeth missing, current orthodontic treatment, and a diagnosis of rheumatoid arthritis.

\section{Instruments}

Evaluations were conducted using the clinical evaluation forms described in detail by Dworkin and LeResche in $1992 .{ }^{16}$ Following were the requirements: a pachymeter (Vonder, Paraná, Brazil) to measure mandibular movements, a metal platform for photographs, a square wooden base, adhesive tape, a tripod (Mirage TT3398, São Paulo, Brazil), a camera (Sony DSC-WX7, Manaus, Brazil), a plumb line (Famastil S.A., Gramado, Brazil), a styrofoam ball, paper markers, and Software for the Assessment of Posture 0.68 (SAPO, São Paulo, Brazil) ${ }^{17}$ available at http://sapo.incubadora.fapesp.br [access in 10 fev 2009].

\section{Evaluation of samples}

The students were examined with the RDC/TMD questionnaire provided by a dentist, who was trained and experienced in the application of this method. Next, the study participants were divided into groups according to RDC axis I, which classifies TMD into three diagnostic groups: group I, muscle disorders; group II, disk displacement; and group III, arthralgia, osteoarthritis, and osteoarthrosis. After clinical evaluation, individuals with TMD were assigned to the study group (SG) and individuals without TMD were assigned to the control group (CG).

\section{Preparation of photographs}

A metal platform was positioned with its base on the ground and a perpendicular rod a tits posterior end. The anterior and lateral sides of the platform were marked with an adhesive tape so that the platform position was recorded, and if necessary, the platform was repositioned. Next, the plumb was hung from a rod parallel to the ground using a black line, and two polystyrene foam (Styrofoam) markers were positioned in the line $50 \mathrm{~cm}$ apart to adjust the scale for the photographic assessment, as requested in the software instructions. A moving wooden base was present in 
the metal outline of the platform, in a standardized position for frontal and sagittal plane photographs.

The camera tripod head was placed at a height of $1.50 \mathrm{~m}$ and at a horizontal distance, parallel to the ground, of $1.50 \mathrm{~m}$ from the center of the anterior end of the platform.

\section{Procedures for photographic records}

\section{Frontal view}

The participant stood on the wooden platform for the frontal photograph. The participant was asked to maintain a natural, relaxed, and comfortable position. The participant's feet were then outlined with a pencil to standardize the position for the frontal and lateral photos.

\section{Lateral view}

The spinous process of the seventh cervical vertebra was identified by palpation after cervical spine flexion by the participant. The participant was asked to move the head back to the neutral position, and a Styrofoam ball and double-faced adhesive tape were used to identify the spinous process and to prevent changes in the position of the marker due to the movement of the skin. The wooden platform was removed and placed back so that the participant would stand in the lateral position.

\section{Criteria to evaluate head posture}

All the photos had a 3-megapixel resolution and could be opened in software to visualize the reference points and the tracings.

\section{Frontal plane criteria}

In this plane, head tilt was evaluated by opening and calibrating the photo according to the SAPO specifications. Next, the "measure angle freely" tool was selected and the tracing was made by moving the mouse along the interpupillary line. ${ }^{18}$ The angle between the interpupillary line and the true vertical line was the measure of head tilt. According to the SAPO software, the normal standard for the angle between the interpupillary line and the true vertical line is 90 degrees. A possible way to evaluate head posture in the frontal plane was previously described by Zepa and Huggare ${ }^{18}$ who used the supraorbital line on a radiograph as a reference to evaluate head tilt. Three measurements were made for each participant, and the mean value was entered as the study value.

\section{Sagittal plane criteria}

The craniovertebral angle described by Visscher et al. ${ }^{19}$ was used to evaluate the head posture in the sagittal plane. The photo was opened in the SAPO software and the "measure angle freely" tool was chosen. Computer-assisted tracing was performed by inserting a straight line that ran through the marker placed on the ear tragus, starting at the marker placed on the spinous process of $\mathrm{C}$. The angle between the line from $\mathrm{C} 7$ to the tragus and the true horizontal line provided by the software defined forward head posture. Three measurements were made for each participant, and the mean value was entered as the study value.

\section{Statistical analysis}

The Kolmogorov-Smirnov test was used to check data normality for craniovertebral angle measurements. The student $t$-test for independent samples or the Mann-Whitney test for data with a nonparametric distribution was used to compare the craniovertebral angle between students previously diagnosed with TMD with students without TMD. A chi-square test was used to evaluate the association between qualitative variables. All analyses were conducted using SPSS, version 13.9 (IBM, Chicago, EUA) and the statistical significance was $5 \%$.

\section{Results}

Table 1 shows the percentages of women and men with TMD and their classification according to the diagnostic type and groups. Group III disorders were predominant among both sexes, and at $>50 \%$ prevalence among the subjects, degenerative processes were found to have a greater prevalence than disk displacement and muscular pain.

Table 2 shows the number of students with and without TMD associated with the presence or absence of abnormal head posture in the frontal plane among women and the prevalence coefficients (PC) and prevalence rate among students with and without head tilt. The PC in the positive group, at $37 \%(0.37)$, refers to TMD prevalence in the group of women with 
Table 1. Percentages of TMD diagnoses among women and men according to RDC/TMD.

\begin{tabular}{|c|c|c|c|}
\hline \multicolumn{2}{|c|}{ Women } & \multicolumn{2}{|c|}{ Men } \\
\hline \multicolumn{2}{|c|}{ Group I } & \multicolumn{2}{|c|}{ Group I } \\
\hline \multicolumn{2}{|c|}{ Myofascial pain } & \multicolumn{2}{|c|}{ Myofascial pain } \\
\hline \multicolumn{2}{|c|}{12.90} & \multicolumn{2}{|c|}{6.25} \\
\hline \multicolumn{2}{|c|}{$\begin{array}{l}\text { Myofascial pain and limited } \\
\text { mouth opening }\end{array}$} & \multicolumn{2}{|c|}{$\begin{array}{l}\text { Myofascial pain and limited } \\
\text { mouth opening }\end{array}$} \\
\hline \multicolumn{2}{|c|}{3,22} & \multicolumn{2}{|c|}{0} \\
\hline \multicolumn{2}{|c|}{ Total } & \multicolumn{2}{|c|}{ Total } \\
\hline \multicolumn{2}{|c|}{16,12} & \multicolumn{2}{|c|}{6,25} \\
\hline \multicolumn{2}{|c|}{ Group II* } & \multicolumn{2}{|c|}{ Group II* } \\
\hline \multicolumn{2}{|c|}{ **DD with reduction } & \multicolumn{2}{|c|}{ DD with reduction } \\
\hline$* * * R$ & $* * * \mathrm{~L}$ & $\mathrm{R}$ & $\mathrm{L}$ \\
\hline 20.96 & 11.29 & 6.25 & 12.5 \\
\hline \multicolumn{2}{|c|}{ Total } & \multicolumn{2}{|c|}{ Total } \\
\hline \multicolumn{2}{|c|}{32.26} & \multicolumn{2}{|c|}{18.75} \\
\hline \multicolumn{2}{|c|}{ Group III } & \multicolumn{2}{|c|}{ Group III } \\
\hline \multicolumn{2}{|c|}{ Arthralgia } & \multicolumn{2}{|c|}{ Arthralgia } \\
\hline$R$ & L & $R$ & L \\
\hline 9.67 & 9.67 & 25 & 6.25 \\
\hline \multicolumn{2}{|c|}{ TMJ osteoarthritis } & \multicolumn{2}{|c|}{ TMJ osteoarthritis } \\
\hline$R$ & L & $R$ & L \\
\hline 8.06 & 4.84 & 6.25 & 6.25 \\
\hline \multicolumn{2}{|c|}{ TMJ osteoarthrosis } & \multicolumn{2}{|c|}{ TMJ osteoarthrosis } \\
\hline$R$ & $\mathrm{~L}$ & $\mathrm{R}$ & L \\
\hline 8.06 & 11.29 & 12.5 & 18.75 \\
\hline \multicolumn{2}{|c|}{ Total } & \multicolumn{2}{|c|}{ Total } \\
\hline & & & \\
\hline
\end{tabular}

TMD: Temporomandibular disorder; TMJ: temporomandibular joint disorder; RDC: research diagnostic criteria.

* Group II includes other conditions, which were not included because not diagnosed.

** Disk displacement.

*** R and L: right TMJ and left TMJ.

head tilt. The PC in the negative group, at $62 \%$ (0.62), refers to the prevalence in the group of women with TMD but no head tilt. The prevalence rate should be greater than 1 , the confidence interval less than 1 , and the p-value less than 0.05 to indicate an association among the variables described in the table.

Table 3 shows the number of men with and without TMD associated with the presence or absence of abnormal head postures in the frontal plane and the prevalence coefficients (PC) and prevalence rate among students with and without head tilt. The prevalence rate should be greater than 1 to indicate an association among the variables.
Table 2. Distribution of the number of women with $(+)$ or without (-) TMD and head tilt.

\begin{tabular}{lcccc}
\hline \multirow{2}{*}{ Women } & $\begin{array}{c}\text { Prevalence } \\
\text { coefficient }\end{array}$ & \multicolumn{2}{c}{ (TMD) } & Total \\
\cline { 2 - 4 } & 0.37 & 20 & 33 & 53 \\
Head tilt + & 0.62 & 15 & 9 & 24 \\
Head tilt - & & 35 & 42 & 77 \\
Total & 0.59 & & & \\
Prevalence rate & & & \\
\hline TMD: Temporomandibular disorder; Confidence interval: 040-098; \\
$\begin{array}{l}\text { p-value: } 0.043 . \\
\text { + presence. } \\
\text { - absence. }\end{array}$
\end{tabular}

Table 3. Distribution of the number of men with $(+)$ or without (-) TMD and head tilt.

\begin{tabular}{lllll}
\hline \multirow{2}{*}{ Men } & $\begin{array}{c}\text { Prevalence } \\
\text { coefficient }\end{array}$ & \multicolumn{2}{c}{ (TMD) } & \multirow{2}{*}{ Total } \\
& 0.28 & 8 & 20 & 28 \\
Head tilt + & 0.14 & 3 & 18 & 21 \\
Head tilt - & & 11 & 38 & 49 \\
Total & 2.0 & & &
\end{tabular}

Prevalence rate $\quad 2.0$

Confidence interval: 0.66-6.57; $p$-value: 0.31

+ presence.

- absence.

Table 4 shows the number of men and women with and without TMD associated with the presence or absence of abnormal head postures in the frontal plane.

No significant differences were found in the angles between individuals with and without TMD. However, among men without TMD, the values were lower for the craniovertebral angle than for the men with TMD. No statistically significant differences were found among women in the SG and CG ( $p=0.701)$ and men $(p=0.213)$. In addition, the cumulative results for women and men in both the SG and CG were not statistically significant $(p=0.123)$.

The data on head tilt angles (Table 5) revealed that right tilt had greater values than left tilt. However, the right and left head tilts were small on the same side in both the SGs and CGs of men and women.

\section{Discussion}

The prevalence of individuals, both women and men, with a diagnosis of TMD according to the RDC/TMD (Table 1) found the most diagnoses in group III (TMJ degenerative changes) followed by group II (disk 
Table 4. Distribution of the number of men and women with $(+)$ or without (-) TMD and head tilt.

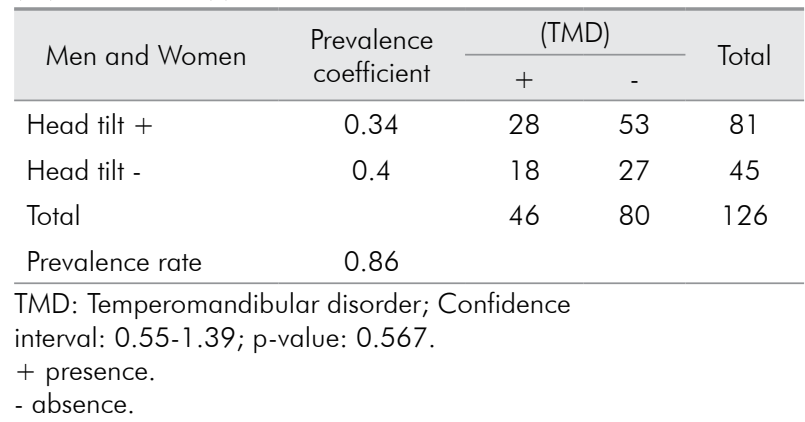

Table 5. Mean, standard deviation, and mean actual change of head tilt angle for men and women with and without TMD.

\begin{tabular}{lcccc}
\hline & \multicolumn{4}{c}{ Groups } \\
\cline { 2 - 5 } & \multicolumn{3}{c}{ Women } & Men \\
\hline Head posture & SG & CG & SG & CG \\
R tilt & $92.97^{*} \pm 1.52^{* *}$ & $93.04 \pm 1.64$ & $93.23 \pm 0.28$ & $92.52 \pm 1.24$ \\
& $2.97^{* * *}$ & $3.04^{*}$ & $3.23^{*}$ & $2.52^{*}$ \\
L tilt & $88.34 \pm 1.85$ & $88.09 \pm 1.26$ & $88.47 \pm 0.29$ & $87.39 \pm 1.18$ \\
& $1.66^{*}$ & $1.91^{*}$ & $1.53^{*}$ & $2.61^{*}$ \\
\hline
\end{tabular}

SG: Study group; CG: control group.

* Angle of head tilt estimated by software.

** Standard deviation.

displacement) with the smallest number in group I (muscle disorders). These results differ from group distribution in the study conducted by Plesh et al..$^{20}$ who used the RDC/TMD and found the greatest prevalence was for muscle changes (group I). However, our results are in agreement with those of Manfredini et al..$^{21}$ who also used the RDC/TMD as a diagnostic tool. A possible explanation for the difference between our findings and those reported by Plesh et al..$^{20}$ may be that their study set composed of only Caucasian and African American women because myofascial pain is more prevalent in women than in men. Manfredini's study evaluated patients under treatment in a private clinic, and their sample composed of men and women with a clinical indication of treatment and variable clinical complaints.

Several methods to evaluate the head posture, particularly in the sagittal plane (lateral view), have been described in the literature. These methods may lead to positive findings in the comparison between head position and temporomandibular dysfunction. ${ }^{2,14,15}$ However, no validation or reliability tests have been used for most methods. In contrast, the craniovertebral angle used in our study to evaluate forward head posture is a highly reliable measurement. ${ }^{20,22,23}$ In addition, the reference of the spinous process of $\mathrm{C} 7$ and the ear tragus are points that define a segment interval only between the head and the neck. Therefore, the reference points for the calculation of the forward head posture (FHP) were minimally affected by distant segments, regardless of individual posture changes. The same has not been found for other methods, such as the plumb line described by Kendall et al..$^{24}$ and used also by Saito et al. ${ }^{15}$ Some studies that used other methods to evaluate FHP, such as the plumb line, but not the craniovertebral angles, have found satisfactory results for the comparison of head posture and TMD..$^{14,25}$

No statistically significant differences were found in craniovertebral angles between the SGs and CGs. Similar results were found by Lunes et al. ${ }^{12}$ who analyzed individuals with the RDC/TMD and measured the craniovertebral angle using a photographic technique. This measure has also been used to evaluate the presence of forward head posture in other studies..$^{20,26}$ In addition, the cross-sectional design of our study precludes us from defining a cause-and-effect relationship between TMD and head posture due to temporal bias.

Most studies ${ }^{2,9,13,14,15,20,23}$ have analyzed only head protrusion in the sagittal plane but the head also moves in the frontal planes, which results in head tilts, and in the transverse plane, which results in rotations. Therefore, it may be inferred that imbalances may exist in tilt and rotation. No studies have taken into consideration the static evaluation of the head in the transverse plane compared with individuals with TMD, probably because of the lack of a validated tool to assess head position in this plane.

A study by Visscher et al. ${ }^{8}$ found that different head postures affect the condylar movement of the TMJ. One posture used in this study was head tilt, which confirmed that during mouth opening, the mandible moved to the side to which the head was tilted. The head tilt angle used for the measurements was 20 degrees. The mean tilt angle in the SG of women in this study (Table 5) was 2.97 degrees to the right and 1.66 degrees to the left. In the SG of men, it was 3.23 degrees to the right and 1.53 degrees to 
the left. These values may not be sufficient to change joint dynamics and cause dysfunction as the head tilt angle in the Visscher et al. ${ }^{8}$ study was much greater.

\section{Conclusion}

In our study sample, no positive correlation was found between forward head posture or head tilt and a diagnosis of TMD.

\section{References}

1. Solow B, Sandham A. Crânio-cervical posture: a factor in the development and function of the dentofacial structures. Eur J Orthod. 2002 Oct;24(5):447-56.

2. Munhoz WC, Marques AP, Siqueira JTT. Radiographic evaluation of cervical spine of subjects with temporomandibular joint internal disorder. Braz Oral Res. 2004 Oct-Dec;18(4):283-9.

3. Sonnesen L, Pedersen CE, Kjaer I. Cervical column morphology related to head posture, cranial base angle, and condylar malformation. Eur J Orthod. 2007 Aug;29(4):398-403.

4. Baydas B, Yavuz I, Durna N, Ceylan I. An investigation of cervicovertebral morphology in different sagittal skeletal growth patterns. Eur J Orthod. 2004 Feb;26(1):43-9.

5. Solow B, Sonnesen L. Head posture and malocclusions. Eur J Orthod. 1998 Dec;20(6):685-93.

6. Davitt BV. Abnormal head posture: a review. Amer Orthoptic J. 2001;51(1)137-43.

7. Olivo SA, Magee DJ, Parfitt M, Major P, Normam MR. The association between the cervical spine, the stomatognathic system, and craniofacial pain: a critical review. J Orofac Pain. 2006 Fall;20(4):271-87.

8. Visscher CM, Huddleston Slater JJR, Lobbezoo F, Naeije M. Kinematics of the human mandible for different head postures. J Oral Rehabil. 2000 Apr;27(4):299-305.

9. Ohmure H, Miyawaki S, Nagata J, Ikeda K, Yamasaki K, Al-kalaly A. Influence of foward head posture on condylar position. J Oral Rehabil. 2008 Nov;35(11):795-800.

10. Svensson P, Wang K, Sessle BJ, Arendt-Nielsen L. Associations between pain and neuromuscular activity in the human jaw and neck muscles. Pain. 2004 Jun;109(3):225-32.

11. Svensson P, Wang K, Arendt-Nielsen L, Cairns BE, Sessle BJ. Pain effects of glutamate injections into human jaw or neck muscles. J Orofac Pain. 2005 Spring;19(2):109-18.

12. Lunes DH, Carvalho LCF, Oliveira AS, Grossi DB. Craniocervical posture analysis in patients with temporomandibular disorder. Braz J Phys Ther. 2009 Jan-Feb;13(1):89-95.

13. Matheus RA, Ramos-Perez FM, Menezes AV, Ambrosano GMB, Haiter-Neto F, Bóscolo FN, et al. The relationship between temporomandibular dysfunction and head and cervical posture. J Appl Oral Sci. 2009 May-Jun;17(3):204-208.

\section{Acknowledgments}

We thank the Universidade de Brasília - UnB, for their full support for the realization of this research. In particular we thank them for the availability of their students.

14. Pedroni CR, Oliveira AS, Guaratini MI. Prevalence study of signs and symptoms of temporomandibular disorders in university students. J Oral Rehabil. 2003 Mar;30(3):283-9

15. Saito ET, Akashi PMH, Sacco ICN. Global body posture evaluation in patients with temporomandibular joint disorder. Clinics. 2009;64(1):35-9.

16. Dworkin SF, LeResche L. Research diagnostic criteria for temporomandibular disorders: review, criteria, examinations and specifications, critique. J Craniomandib Disord. 1992 Fall;6(4):301-55.

17. Ferreira EAG, Duarte M, Maldonado EP, Burke TN, Marques AP. Postural assessment software (PAS/SAPO): validation and reliability. Clinics. 2010 Jul;65(7):675-81.

18. Zepa I and Huggare J. Reference structures for assessment of frontal head posture. Eur J Orthod. 1998 Dec;20(6):694-9.

19. Visscher CM, Boer W, Lobbezoo F, Habets LLMH, Naeije M. Is there a relationship between head posture and craniomandibular pain? J Oral Rehabil. 2002 Nov;29(11):1030-6.

20. Plesh O, Sinisi SE, Crawford PB, Gansky AS. Diagnoses based on the Research Diagnostic Criteria for Temporomandibular Disorders in a biracial population of young women. J Orofac Pain. 2005 Winter;19(1):65-75.

21. Manfredini D, Piccotti F, Ferronato G, Guarda-Nardini L. Age peaks of different RDC/TMD diagnoses in a patient population. J Dent. 2010 May;38(5):392-9.

22. Lee WY, Okeson JP, Lindroth J. The relationship between forward head posture and temporomandibular disorders. J Orofac Pain.1995 Spring;9(2):161-7.

23. Brunton J, Brunton E, Mhuiri AN. Reliability of measuring natural head posture using the craniovertebral angle. Irish Ergon Rev. 2003;7(3): 37-41.

24. Kendall FP, McCreary EK, Provance PG, Rodgers MM, Romani WA. Muscles:Testing and function, with posture and pain. 5th ed. Barueri: Manole; 2007. p. 60-86.

25. Strini PJSA, Machado NAG, Gorreri MC, Ferreira AF, Sousa GC, Fernandes Neto AJ. Postural evaluation of patients with temporomandibular disorders under use of occlusal splints. J Appl Oral Sci. 2009 Sep-Oct;17(5):539-43.

26. Raine S, Twomey LT. Head and shoulder posture variations in 160 asymptomatic women and men. Arch Phys Med Rehabil. 1997 Nov;78(11):1215-23. 